\title{
Japan Expects Decrements in Both the Incidence and Mortality of Acute Myocardial Infarction in the Modern Era:
}

\author{
Likely or Just a Dream?
}

\author{
Masanori Asakura, MD; Tetsuo Minamino, MD*; Masafumi Kitakaze, MD
}

A cute myocardial infarction (AMI) is a leading cause of death, not only in Japan but also worldwide. In Japan in particular, AMI is becoming an increasingly important disease, primarily because of the progressive westernization of lifestyle habits and the rapid aging of society over the past 50 years. Concomitantly, during the past 2 decades the prevention and treatment of AMI has advanced dramatically, because we treat the involved coronary artery lesions using various interventional strategies. ${ }^{1}$ In the current era, when the various factors related to AMI have undergone rapid change, it is becoming increasingly important to assess the temporal trends in AMI in the Japanese population.

\section{Article p 93}

Since the 1990s, various recanalization strategies, such as percutaneous coronary intervention and thrombolysis, have been performed in the acute phase treatment of AMI. The introduction of these reperfusion therapies has led to a substantial decrease in the short- and long-term mortality in developed countries, ${ }^{1-3}$ including Japan. ${ }^{4}$ The $4 \mathrm{~S}$ and WOSCOPS large clinical trials in $1994^{5}$ and $1995,{ }^{6}$ respectively, were the first to demonstrate that pravastatin decreased nonfatal MI. Following these trials, the usage of statins for high-risk patients increased dramatically for the primary or secondary prevention of AMI. As a consequence, total cholesterol levels in the population have decreased in Western countries, and these preventative treatments for AMI have contributed to a steady decline in its incidence. ${ }^{7}$ Thus, the incidence and mortality of AMI has declined substantially during the past decades in most developed countries. Conversely, in Japan the incidence of AMI is considered to have increased, mainly as a consequence of rapidly progressing westernization of lifestyle and the aging of society. Nevertheless, although there were a few studies on acute myocardial infarction in the $2000 \mathrm{~s},{ }^{8}$ actual trends in the incidence and mortality remain unclear.

In this issue of the Circulation Journal, Takii et al describe the trends in AMI over the past 30 years in the northeastern district of Japan. ${ }^{9}$ They registered 22,551 patients with AMI who were admitted to 43 hospitals in Miyagi Prefecture between 1979 and 2008. This Miyagi-AMI registry study revealed that the overall age-adjusted in-hospital mortality for AMI has decreased from $20 \%$ in 1979 to $8 \%$ in 2008 . A particularly marked decline in mortality was observed between the 1980s and 1990s. This decline is suggested to be attributable to advances in reperfusion therapies, including primary percutaneous coronary intervention. This downward trend in mortality in Japan mirrors that in Western countries.

On the other hand, the Miyagi-AMI registry study also revealed that the overall age-adjusted incidence of AMI has increased from 7.4 per 100,000 in 1979 and to 27.0 per 100,000 in 2008 . The incidence increased markedly between 1979 and 2003, although the rate of increase now appears to have reached a plateau. Furthermore, an increasing trend in the age-adjusted incidence rate of AMI was also observed in a Takashima AMI registry study from 1990 through $2001,{ }^{8}$ A marked increase in incidence was observed from $7.4 / 100,000$ to approximately $20 / 100,000$ during the early 1980s and appears to be due to advances in the ability to diagnose AMI, including the introduction of emergency angiography, in Japan. Given that this was a hospital-based cohort study, the increase recorded may reflect the concentration of patients with AMI in the large hospitals with coronary care units after the 1980s. This trend in the incidence of AMI in Japan is apparently different from the trend in Western countries - a difference that may be attributed to the westernization of lifestyle and dietary habits and to the rapidly aging society in Japan over the past few decades. The westernization of Japanese lifestyle and dietary habits has caused changes in the classic risk factors for AMI, including dyslipidemia, diabetes mellitus, hypertension, and smoking. A national nutrition survey in Japan revealed that the plasma total cholesterol level increased from $180 \mathrm{mg} / \mathrm{dl}$ in 1980 to $200 \mathrm{mg} / \mathrm{dl}$ in 1990, and that it remained elevated after that period. In contrast, in the United States, a substantial decrease in plasma total cholesterol level was observed over the same period. This difference in the trend of total cholesterol level may partly explain the differences in the incidence of AMI observed in Japan and the United States. The Japanese survey data also show that the prevalence of diabetes mellitus substantially increased between 1997 and 2007. Furthermore,

The opinions expressed in this article are not necessarily those of the editors or of the Japanese Circulation Society.

Received November 12, 2009; accepted November 13, 2009

Department of Research and Development of Clinical Research, National Cardiovascular Center, *Department of Cardiovascular Medicine, Osaka University Graduate School of Medicine, Suita, Japan

Mailing address: Masanori Asakura, MD, Department of Research and Development of Clinical Research, National Cardiovascular Center, 5-7-1 Fujishirodai, Suita 565-8565, Japan. E-mail: masakura@hsp.ncvc.go.jp

ISSN-1346-9843 doi:10.1253/circj.CJ-09-0885

All rights are reserved to the Japanese Circulation Society. For permissions, please e-mail: cj@j-circ.or.jp 
the survey revealed that both systolic blood pressure and smoking have steadily decreased in the population. During this period of major risk factor changes, various prevention and treatment strategies for AMI, such as aspirin, statins, and percutaneous coronary intervention, have been introduced. During the 1990s, large clinical trials demonstrated the beneficial effects of angiotensin-converting enzyme (ACE) inhibitors and statins. ${ }^{5,6,10}$ After those trials, the usage of ACE inhibitors and statins increased dramatically in the prevention and treatment of AMI. Thus, the impact of these several factors on the incidence of AMI tends to make the situation more complex. The current trend in Japan suggests that greater emphasis needs to be placed on aggressive prevention and treatment. ${ }^{11,12}$ The MIYAGI-AMI registry study indicates that the incidence of AMI in Japan peaked around 2003. It is important that we determine whether the incidence will continue to increase or decline in the future.

Importantly, the present study reveals that the number of elderly patients admitted with AMI has steadily increased, particularly women, over the past 2 decades. The decreasing incidence of mortality from AMI appears to have slowed down since 2000, possibly because of the increasing age of the patient population with AMI. It therefore seems a critical issue to devise an appropriate treatment strategy for these elderly patients.

The present study emphasizes another important finding, namely, that over the years studied, women had higher rates of in-hospital mortality because of AMI than men. In 2008, in-hospital deaths were twice as high in women (12\%) as they were in men $(6 \%)$. Interestingly, the gender difference in in-hospital mortalities from AMI has been observed in several other studies. ${ }^{2,13}$ The cause of the higher mortality in women appears to be multifactorial. The present study showed that women developed MI 10 years later than men. In 2008 , the percentage of male patients aged 80 years or over was $15 \%$, whereas for females it was $50 \%$. Elderly patients with AMI appear to be less likely to receive reperfusion therapies, including percutaneous coronary intervention, because of the risk of complications. Women also appear to have more coronary risk factors at baseline, such as dyslipidemia, diabetes mellitus, and hypertension, when compared with men. These factors, such as older age, more severe risk factors, and concomitant disorders, correspond with the higher rates of in-hospital mortality in women. Accordingly, concerted efforts must be made to decrease the mortality in women presenting with AMI.

This report provides extremely useful information on the epidemiology of AMI over the past 30 years in Japan. It shows that, in contrast to Western countries, the incidence of AMI is increasing in Japan. The evidence presented here suggests that greater emphasis needs to be placed on preven- tion and treatment of AMI in Japan than in Western counties. Last but not least, this intriguing and challenging study suggests the importance of prevention and treatment for both elderly and women patients with AMI.

\section{References}

1. Kuch B, Heier M, von Scheidt W, Kling B, Hoermann A, Meisinger C. 20-year trends in clinical characteristics, therapy and short-term prognosis in acute myocardial infarction according to presenting electrocardiogram: The MONICA/KORA AMI Registry (19852004). J Intern Med 2008; 264: 254-264.

2. Movahed MR, John J, Hashemzadeh M, Jamal MM. Trends in the age adjusted mortality from acute ST segment elevation myocardial infarction in the United States (1988-2004) based on race, gender, infarct location and comorbidities. Am J Cardiol 2009; 104: $1030-1034$.

3. Briffa T, Hickling S, Knuiman M, Hobbs M, Hung J, Sanfilippo FM, et al. Long term survival after evidence based treatment of acute myocardial infarction and revascularisation: Follow-up of population based Perth MONICA cohort, 1984-2005. BMJ 2009; 338: b36.

4. Watanabe J, Iwabuchi K, Koseki Y, Fukuchi M, Shinozaki T, Miura M, et al. Declining trend in the in-hospital case-fatality rate from acute myocardial infarction in Miyagi Prefecture from 1980 to 1999. Jpn Circ J 2001; 65: $941-946$.

5. Randomised trial of cholesterol lowering in 4444 patients with coronary heart disease: The Scandinavian Simvastatin Survival Study (4S). Lancet 1994; 344: 1383-1389.

6. Shepherd J, Cobbe SM, Ford I, Isles CG, Lorimer AR, MacFarlane PW, et al. Prevention of coronary heart disease with pravastatin in men with hypercholesterolemia: West of Scotland Coronary Prevention Study Group. N Engl J Med 1995; 333: 1301 - 1307.

7. Movahed MR, Ramaraj R, Hashemzadeh M, Jamal MM. Rate of acute ST-elevation myocardial infarction in the United States from 1988 to 2004 (from the Nationwide Inpatient Sample). Am J Cardiol 2009; 104: 5-8.

8. Rumana N, Kita Y, Turin TC, Murakami Y, Sugihara H, Morita Y, et al. Trend of increase in the incidence of acute myocardial infarction in a Japanese population: Takashima AMI Registry, 1990-2001. Am J Epidemiol 2008; 167: 1358-1364.

9. Takii T, Yasuda S, Takahashi J, Ito K, Shiba N, Shirato K, et al. Trends in acute myocardial infarction incidence and mortality over 30 years in Japan: Report from the MIYAGI-AMI Registry Study. Circ J 2010; 74: 93-100.

10. Pfeffer MA, Braunwald E, Moye LA, Basta L, Brown EJ Jr, Cuddy TE, et al. Effect of captopril on mortality and morbidity in patients with left ventricular dysfunction after myocardial infarction. Results of the survival and ventricular enlargement trial: The SAVE Investigators. N Engl J Med 1992; 327: 669-677.

11. Sato H, Kinjo K, Ito H, Hirayama A, Nanto S, Fukunami M, et al. Effect of early use of low-dose pravastatin on major adverse cardiac events in patients with acute myocardial infarction: The OACISLIPID Study. Circ J 2008; 72: 17-22.

12. Takeno M, Yasuda S, Otsuka Y, Morii I, Kawamura A, Yano K, et al. Impact of metabolic syndrome on the long-term survival of patients with acute myocardial infarction: Potential association with C-reactive protein. Circ J 2008; 72: 415-419.

13. Lundblad D, Holmgren L, Jansson JH, Naslund U, Eliasson M. Gender differences in trends of acute myocardial infarction events: The Northern Sweden MONICA study 1985-2004. BMC Cardiovasc Disord 2008; 8: 17. 